\title{
A new species of Serracutisoma (Opiliones: Gonyleptidae: Goniosomatinae) from the coastal Atlantic Rain Forest of Paraná and São Paulo states, Brazil
}

\author{
Marcio B. DaSilva
}

Departamento de Sistemática e Ecologia/CCEN Universidade Federal da Paraíba. Cidade Universitária, 50051-970 João Pessoa, PB, Brazil.E-mail:1940@uol.com.br

\begin{abstract}
Serracutisoma gnaspinii sp. nov. is described from the coastal Ombrophylous Dense Atlantic Rain Forest of Paraná and São Paulo states. It differs from other Serracutisoma by having a retrolateral row of spines on femur IV, a rounded white-mark on the carapace and a low dorsal apophysis on trochanter IV. It is likely the sister-species of $S$. proximum, and with it and other five species forms the S. proximum group, herein formally proposed. Given that the biologic, phylogenetic and biogeographic aspects of Serracutisoma have been studied, the implications of the discovery of a new species are discussed, for instance the evolution of male fight, aggregation and maternal care, traits that are shared with other species. The geographic range of Serracutisoma gnaspinii sp. nov. is compatible with the "Paraná" area of endemism, but with an unique distribution pattern compared to other endemic harvestmen species, which could indicate a new area of endemism also occupied by the primate Leontopithecus caissara Lorini \& Persson, 1990.
\end{abstract}

KEY WORDS. Alpha and beta males; biogeography; territorial fights; Tropical Rain Forest; vicariance.

Goniosomatinae Mello-Leitão, 1935 harvestmen are large, colorful, conspicuous, and inhabit humid forests of eastern Brazil. The subfamily is one of the eight subfamilies of Gonyleptidae that are endemic to the Atlantic Rain Forest. The restricted distribution of the species of this subfamily is associated with a number of main geographical barriers, which have been uncovered by a number of studies that have shown that Goniosomatinae make good models for Historical Biogeography (e.g., Pinto-Da-Rocha et al. 2005, DaSilva \& Pinto-Da-Rocha 2011). Several biological aspects of Goniosomatinae species have been studied, for instance reproductive biology (e.g., Buzatto et al. 2011), speleology (e.g., Chelini et al. 2011), behavior (e.g., MACHADO et al. 2000), population ecology (e.g., WiLlemart \& GNASPINI 2004) etc. Upon reviewing the family and constructing a phylogenetic hypothesis for it based on morphology, DASILVA \& GNASPINI (2010) listed 37 species distributed in six genera. Later, Ázara et al. (2013) described an additional species and extended the distribution of the subfamily to the north. Presently, species of Goniosomatinae are known from the state of Pernambuco, Northern Brazil, to the state of Santa Catarina in the South, covering almost the entire Atlantic Forest. However, species of this subfamily do not occur in the Semidecidual interior forest associated with the Paraná River Basin.

Serracutisoma Roewer, 1930 is composed of 10 species that are distributed from the state of São Paulo to the state of Santa Catarina (DASILVA \& GNASPIN 2010). Serracutisoma spelaeum (MelloLeitão, 1933), S. proximum (Mello-Leitão, 1922), S. guaricana
DaSilva \& Gnaspini, 2010, S. molle (Mello-Leitão, 1933), S. pseudovarium DaSilva \& Gnaspini, 2010, and S. catarina (Machado, Pinto-da-Rocha \& Giaretta, 2002) were used as models in biological studies (e.g., Chelini et al. 2011, Buzatto et al. 2011, Oliveira et al. 2006, MACHADO et al. 2002, respectively). Serracutisoma spelaeum, $S$. proximum, $S$. molle and $S$. pseudovarium are trogloxen species; the former is restricted to caves (DASILVA \& GNaspini 2010). The other species in the genus are Serracutisoma fritzmuelleri DaSilva \& Gnaspini, 2010, S. inerme (Mello-Leitão, 1927), S. banhadoae (Soares \& Soares, 1947) and S. thalassinum (Simon, 1879).

In the present work, a new species of Serracutisoma is described from the coastal region of the southern portion of São Paulo and northern portion of the state of Paraná. The biologic, phylogenetic and biogeographic implications of the discovery of this new species are discussed.

\section{MATERIAL AND METHODS}

External morphology and penis were studied under a stereomicroscope. Body and appendages were measured using a caliper, and measurements of granules were made under the stereomicroscope. Morphological terminology follows DASILVA \& GNASPINI (2010).

Type specimens were deposited in the Museu de Zoologia, Universidade de São Paulo (MZSP), Museu de História Natural Capão do Imbuia, Prefeitura Municipal de Curitiba (MHNCI) and Coleção de Entomologia, Universidade Federal da Paraíba (UFPB). 


\section{TAXONOMY}

DaSilva \& GNaSpini (2010) presented detailed diagnoses of Goniosomatinae and Serracutisoma, providing an extensive list of morphological characters of the external anatomy and penis that are shared by all species at each taxonomic rank. A summarized diagnosis of Serracutisoma is presented here for easy identification of specimens. The new species is described, but the characters defined as diagnostic for Goniosomatinae DASILVA \& GNASPINI 2010) are not included.

\section{Serracutisoma Roewer, 1930}

Type species. Acutisoma proximum Mello-Leitão, 1922, by monotypy.

Synonyms. Acutisomelloides Mello-Leitão, 1932, Spelaeosoma Mello-Leitão, 1933, and Pygosomoides Mello-Leitão, 1933.

Condensed diagnosis. Male: femur IV armed with retrolateral spines; prolateral apophysis of coxa IV with falcate apex; trochanter IV with the following apophyses: pointed distal retrolateral; distal dorsal, curved inward; and basal prolateral; femur III armed ventrally. Female: Separated and rounded pair of tubercles on ocularium; differs from Heteromitobates, Mitogoniella and Acutisoma by not having punctuated white drymarks on lateral margin of dorsal scute, differs from Goniosoma and Pyatan by not having spines on ocularium.

Distribution of species. Santa Catarina, Paraná and southern São Paulo.

\section{Serracutisoma gnaspinii sp. nov.} Figs 1-6

Description of male (condition described within parentheses pertains to the holotype): Dorsum (Figs 1 and 6): eyemound low with 1 pair of round tubercles as high as wide. Area I with main pair of elevations indistinct; area III with 1 pair of medium spines slightly pointed backward. Angles of posterior margin with a pair of tubercles similar to those of eye-mound; angles of free tergites and anal operculum with spines twice as large as tubercles of posterior margin of dorsal scute. Granulation (Fig. 1). Carapace: 11-20 (16) small-sized granules. Areas I-III: 18-29 (25) small-sized granules. Lateral margin, posterior margin and free tergites: low density of medium-sized granules. Anal operculum: low density of minute granules. Venter: posterior margin of stigmatic area and free sternites: low density of minute granules. Coxa I: low density of minute granules. Coxa IV: low density of minute granules; lateral: medium granules. Chelicerae: segment I with 3 pairs of minute granules, 2 basal and 1 apical. Segment II with medium density of medium granules. Pedipalps: trochanter with 3 dorsal and 3 ventral elevations. Femur with 5-8 (5/6) ventral elevations (standard armature Iiiiliii), 1 retrolateral subapical seta and dorsal granulation with low density of minute granules. Patella: small ventro-prolateral subapical tubercle like a small granule. Tibia: with low retrolateral sub-basal tubercle and low density of ventral medium granules, in addition to the standard armature of subfamily: tibia with ventral armature IiIi prolaterally and IiIIi retrolaterally; tarsus with ventral armature IIi prolaterally and IiIi retrolaterally. Leg I: Trochanter smooth, except standard tubercles of subfamily. Femur and patella with small granules. Tibia and metatarsus with minute granules. Leg II: Trochanter with minute granules, in addition to standard tubercles of subfamily. Femur and patella with small granules. Tibia with sparse minute spines on row 4 and minute granules in other rows. Metatarsus with minute granules. Leg III: Femur armed with sparse and slightly curved spines on row 3 increasing in size apically. Trochanter with low density of minute granules. Femur, patella and tibia with small granules. Metatarsus with minute granules. Leg IV (Figs 2 and 3): Large prolateral apical apophysis of coxa almost transversal, with falcate apex with a short dorsal branch; retrolateral apical apophysis spiniform similar in size to the spines of angles of free tergites. Trochanter with basal prolateral apophysis, dorso-prolateral apical apophysis very reduced, resembling a callus, and retrolateral apical apophysis curved backward and twice the size of retrolateral apophysis of coxa. Femur straight with medium pointed granules, larger on ventral rows; row2 armed in its entire extension with medium spines alternating with normal granules; dorsal apical apophyses small, subequal in size. Patella and tibia with medium pointed granules, larger on ventral rows. Tarsal process minute and tarsal claws smooth. Tarsal segmentation: 9-12 (12), 19-24 (22/23), 10-13 (13), 1114 (14). Penis (Figs 4 and 5): ventral plate hexagonal with concave apical margin, shallow V-shaped; ventral surface smooth. Apical group with dorsal row of 5 setae with the more ventral seta on medial region (second and last, from apex to base, smaller); basal group transversal (or almost) with 4 setae; all setae spatulate and wide. Glans with ventral process bearing narrow and V-shaped apical lamina, inserted at base, and apical margin with many small projections; without dorsal process; stylus cylindrical. Truncus invading ventral plate medially on dorsal surface. Color pattern (Fig. 6). Dorsal scute reddishdark-brown with margins, granules and tubercles yellowish; pedipalps and chelicerae dark green; legs I-III and venter reddish-brown; leg IV and spine of area III of dorsal scute black; joint tibia and metatarsus with conspicuous lighter ring. Drymark following grooves of areas and as longitudinal thin stripe on abdominal scute and resembling rounded and striped spot behind eye-mound on carapace (see 'mask' and 'frame' definitions in DaSilva \& GNaspini 2010), on apex of coxa continuous on entire trochanter and base of femur of leg IV - variation: dry-marks varies significantly among individuals, but following the general pattern described above; see ÁzARA et al. (2013) for discussion on polymorphism in dry-marks. Black articular membranes between coxae and trochanters with dry-mark.

Measurements (in mm). Dorsal scute: width: 6.53-8.95 (8.91), length: 6.80-9.46 (9.41); leg I: 40.12-51.19 (51.03), II: 

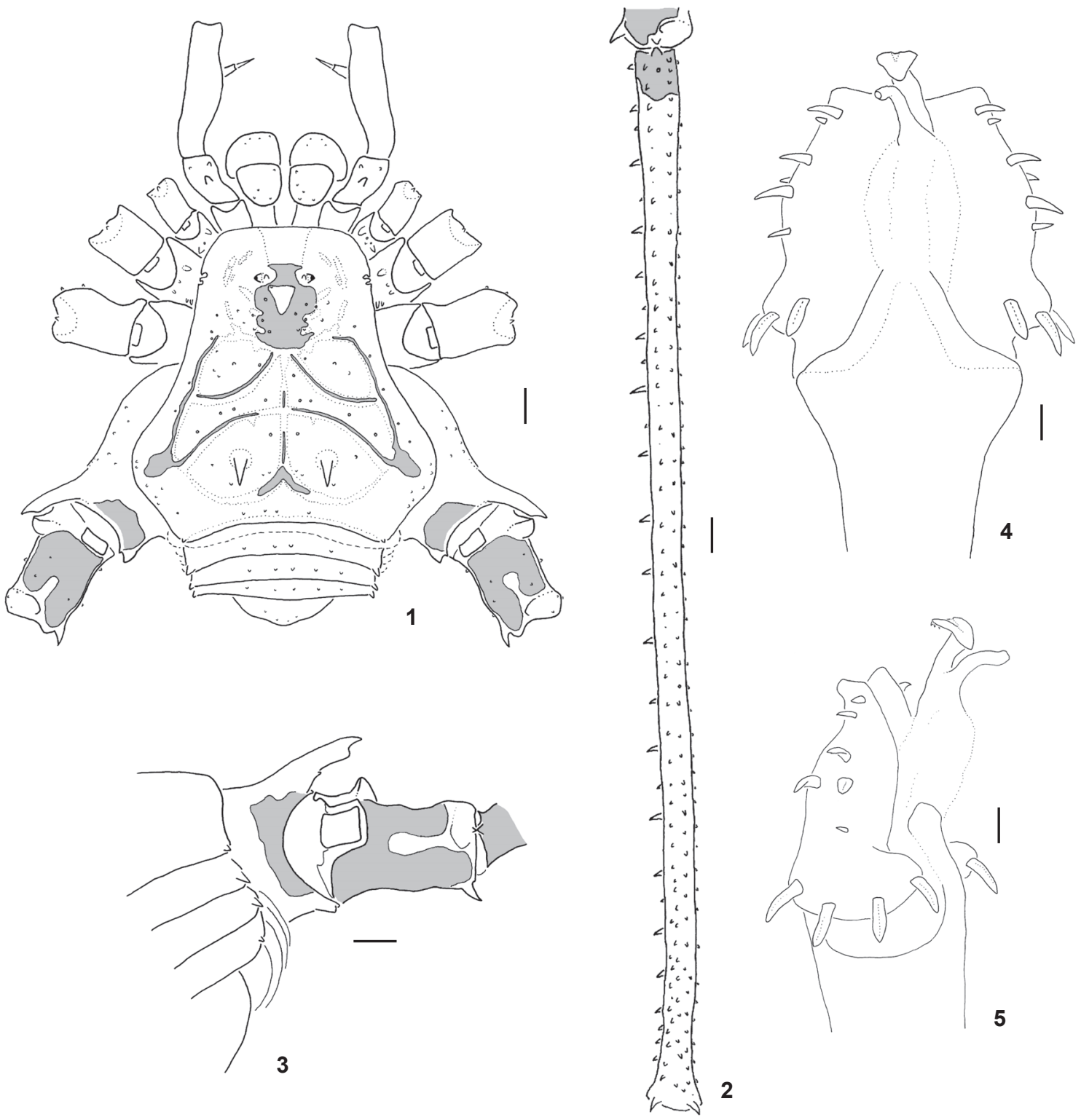

Figures 1-5. (1-3) Male holotype (MZSP 18952) of S. gnaspinii sp. nov.: (1) dorsal habitus; (2) right trochanter and femur IV, dorsal view; (3) detail of apexes of right coxa IV and dorsal scute, free tergites and trochanter IV, retrolateral view; note falcate apophysis of coxa. Gray patches represent white dry-marks. (4-5) Penis of paratype (MHNCl 6777): (4) dorsal view; (5) lateral view. Scale bars: 1-3 $=1 \mathrm{~mm}, 4-5=0.05 \mathrm{~mm}$.

94.72-128.64 (127.31), III: 60.23-77.32 (76.35), IV: 78.31-100.41 (100.41).

Male dimorphism. Males have two morphs, alpha and beta (or majors and minors), as recorded for species of other seven families of Laniatores (DASILVA \& KuRY 2007). As in other gonyleptid, beta specimens of Serracutisoma gnaspinii sp. nov. are smaller and the sexual secondary armature of leg IV is less developed, with smaller spines and apophyses, including ab- sence of some smaller spines of alpha. Beta specimens also have much shorter legs II (less armed too) and IV. The more representative beta (and smaller) specimen of the examined material is the UFPB 144 .

Female. Sexual dimorphism in legs II-IV (less armed and shorter in female), angles of free tergites (more armed in female) and tarsal process (smaller in female), as in all species of Goniosomatinae. Angles of free tergites with spines of same 


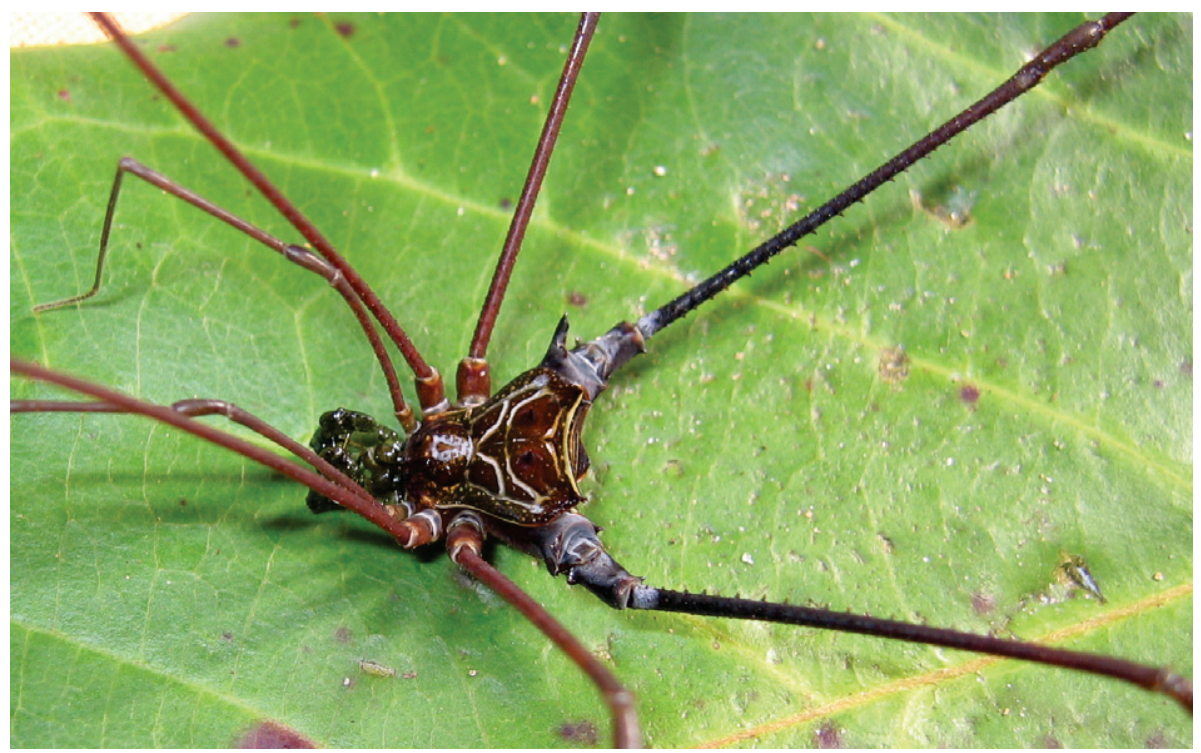

Figure 6. Living male of S. gnaspinii sp. nov. from Barra do Turvo (MZSP 25777 paratype).

size of those of area III, but more robust; angles of posterior margin of dorsal scute with spines half the size of spines of free tergites. Femora III-IV and tibia II unarmed. Leg IV darkbrown. Measurements (in mm). Dorsal scute: width: 7.67-8.15, length: 7.86-8.12; leg I: 40.25-42.95, II: 89.87-94.52, III: 60.5963.39, IV: 80.05-84.35.

Material examined. BraziL, São Paulo: Cananéia (Ilha do Cardoso), ma holotype and 2 ma and 3 fe paratypes (MZSP 18952), G. Machado leg., 12-18/I/2000; idem, 1 male paratype (UFPB 144), F.H. Santos leg., 16/IX/2000; Cananéia (Ilha do Cardoso, Cachoeira do Ipanema), 1 male and 4 females paratypes (UFPB 145), A.C. Marques, leg., 9/IV/2001; Cananéia (Serra do Itapitangui, estrada para Ariri, km 9), 1 male and 1 female paratypes (MZSP 57281), M.B. da Silva et al., leg., 2/II/ 2006; Barra do Turvo (pé da Serra do Cadeado, km 523 da BR116, 680m), 13 males and 4 females paratypes (MZSP 29577; photographed individual, Fig. 6), M.B. da Silva et al. leg., 1/II/2006. Paraná: Guaraqueçaba (waterfall of a small stream, on rock), 2 ma paratypes (MZSP 19521), G. Montingelli leg., 25/III/2000; Guaraqueçaba (PR-405, estrada para Curitiba), 2 males and 4 females paratypes (MZSP 57282), M.B. da Silva et al. leg., XII/ 2005; Guaraqueçaba (Ilha de Superagui, Barra do Arararipa), 1 male and 1 female paratypes (MHNCI 6777), M.R. Bornschein \& V.G. Persson leg., 18/II/1990.

Distribution. Coastal plain of southern São Paulo and northern Paraná and adjacent slopes of the eastern crystalline plateau of Serra do Mar.

Etymology. The epithet gnaspinii honors Dr. Pedro Gnaspini, my former advisor, who worked extensively on Goniosomatinae and who best knows the intimate life of a goniosomatine harvestman.
Remarks. According to the phylogenetic hypothesis of DaSilva \& Gnaspini (2010), Serracutisoma is divided in two clades of species, here formally named $S$. proximum and $S$. inerme groups.

Comparative diagnosis. The new species is similar to $S$. proximum and $S$. thalassinum by having a row of retrolateral spines over the entire femur IV of the male. The dry-mark on the abdominal scute (both sexes) is similar to that of $S$. proximum, $S$. fritzmuelleri and $S$. catarina, i.e., following grooves of areas, as a "frame/mask" (DASILVA \& GNASPINI 2010), but on the carapace it is rounded and large ("frame"), instead of a ' $\mathrm{Y}$ 'like mark. The new species also differs from $S$. proximum by not having dorsal spines on femur IV and light rings around femoral apexes, and by having a reduced (very shallow) dorsal apical apophysis on male trochanter IV. Females of $S$. gnaspinii also differ from females of $S$. proximum by not having spines on femur IV.

\section{Serracutisoma proximum group}

S. proximum (Mello-Leitão, 1922)

S. gnaspinii sp. nov.

S. banhadoae (Soares \& Soares, 1947)

S. molle (Mello-Leitão, 1933)

S. pseudovarium DaSilva \& Gnaspini, 2010

S. thalassinum (Simon, 1879)

S. fritzmuelleri DaSilva \& Gnaspini, 2010

Diagnosis. Males generally blackish, mainly on leg IV, large spines and apophyses; females of some species greenish; most species (except $S$. banhadoae, $S$. pseudovarium and $S$. gnaspinii sp. nov.) present sexual dimorphism in coloration, 
females presenting fragmented dark pigmentation on areas of dorsal scute. Prolateral apophyses of coxa IV oblique.

\section{Serracutisoma inerme group}

S. inerme (Mello-Leitão, 1927)

S. guaricana DaSilva \& Gnaspini, 2010

S. spelaeum (Mello-Leitão, 1933)

S. catarina (Machado, Pinto-da-Rocha \& Giaretta, 2002)

Diagnosis. Both sexes with general brownish/yellowish coloration, without sexual dimorphism in color. Males with large retrolateral spines from basis to median portion of femur IV, spines on apical portion of tibia IV, two or three distinct large spines on apical portion of femur II and III and transversal and long prolateral apophyses of coxa IV.

\section{DISCUSSION}

Upon optimizing the character state changes in the phylogeny of DASILVA \& GNASPINI (2010), using ACCTRAN (accelerated transformation), I infered that Serracutisoma gnaspinii sp. nov. is likely the sister-species of $S$. proximum, based on following putative synapomorphies: large spines over entire extension of male femur IV, sparse spines on male femur III, white dry-mark covering entire dorsum of trochanter IV. When DELTRAN (delayed transformation) is used to optimize the characters, the absence of spines on venter of male femur IV and presence of spines on angles of male free tergites are also synapomorphies for these two species.

Specimens of $S$. gnaspinii sp. nov. were collected in three different localities. The life history of individuals is compatible with the general pattern of goniosomatine, which is common to species of five genera in the subfamily (e.g., Machado 2002, CAETANO \& Machado 2013): individuals live in very humid habitats, normally aggregating on and under rocks, large trunks, and vegetation near to rivers. Females of the new species have also been found guarding eggs.

BuzatTo et al. (2011) described the reproductive strategies of Serracutisoma proximum. In the latter, there are two male morphs, major and minor (or alpha and beta), in the same population. Major males use leg II as weapon in ritualistic fights. ÁzAra et al. (2013) hypothesized that the use of leg II to fight also occurs in some species of Mitogoniella. In this genus, the length of leg II varies widely among individuals, which is possibly the result of selection favoring two morphs, as it could also be the case of the spines on tibia of leg II. Serracutisoma gnaspinii sp. nov. also has spines on tibia II, located on row 3 , as $S$. proximum does. Six other species of Serracutisoma have those spines, whose disposition on leg II varies widely from one species to another: $S$. banhadoae, row 2 of tibia and metatarsus, S. molle, rows 3 and 4 of tibia, $S$. thalassinum, rows 3 and 4 of tibia and metatarsus, $S$. catarina, rows 4 and 5 of tibia and row 4 of metatarsus, $S$. inerme, row 4 of tibia and metatarsus, $S$. guaricana, rows 3 and 4 of tibia, and S. spelaeum, row 6 of tibia and row 4 of metatarsus; S. fritzmuelleri and S. pseudovarium have unarmed legs II (DASILVA \& GNASPINI 2010). This interesting inter-specific variation could indicate that the leg armature arose independently, and is likely to be used in male agonistic behaviors. However, this variation could be explained by parallel evolution. These hypotheses deserve further morphological, morphometrical and biological studies of Serracutisoma species.

Serracutisoma gnaspinii sp. nov. is distributed in a coastal plain and adjacent plateau slopes, in a region that does not harbor other Serracutisoma species, and which is limited by the Ribeira do Iguape River to the north, Serra do Mar to the west and Paranaguá bay to the south. Its sister species, $S$. proximum, inhabits the northern portion of the Ribeira do Iguape River, also in the coastal plain, while other species of $S$. proximum group live on the plateau of Serra do Mar to the interior (Fig. 7). Pinto-Da-Rocha et al. (2005) and DaSilva \& PinTo-DA-Rocha (2011) delimited an area of endemism in this region based on the distributions of six species of five subfamilies of Gonyleptidae, which they named "Paraná". The core of this endemism region is in the Serra do Mar plateau of the state of Paraná. The ranges of Serracutisoma gnaspinii sp. nov., Cadeadoius niger (Mello-Leitão, 1935) (Progonyleptoidellinae) and Pseudotrogulus trotskii DaSilva \& Pinto-da-Rocha, 2010 (Hernandariinae) compose a Maximum Region of Endemism of the area of endemism, i.e., they have unique distributions compared to those of the core area (on plateau), but are restricted in the area of endemism and limited to the north by the Ribeira do Iguape River (Fig. 7 and DASILVA \& PINTO-DA-Rocha 2011). A primate, the critically endangered black-faced lion tamarin Leontopithecus caissara Lorini \& Persson, 1990 (NAscimento et al. 2011), has the same distribution range as $S$. gnaspinii sp. nov., which could indicate a new area of endemism for this region that is separated from "Paraná". Thus, this new species can greatly contribute to biogeographic studies that aim to understand the processes that have created these endemism patterns, with the Ribeira do Iguape River ruling as a vicariant barrier or a separation between lowlands/montane forests. Additionally, S. gnaspinii sp. nov., can contribute to the understanding of processes related to individual species, as for instance the probability that the coastal plains have been colonized more recently from the core of previously delimited areas of endemism, a more stable forested area in geological time.

\section{ACKNOWLEDGEMENTS}

I thank Marcos Hara and Fabiana Pioker for help during collecting trips, two anonymous referees for helpful suggestions on the manuscript and the curators who loaned the material. Fundação de Amparo à Pesquisa do Estado de São Paulo provided fellowship (MBS, FAPESP \#03-02673-0). 


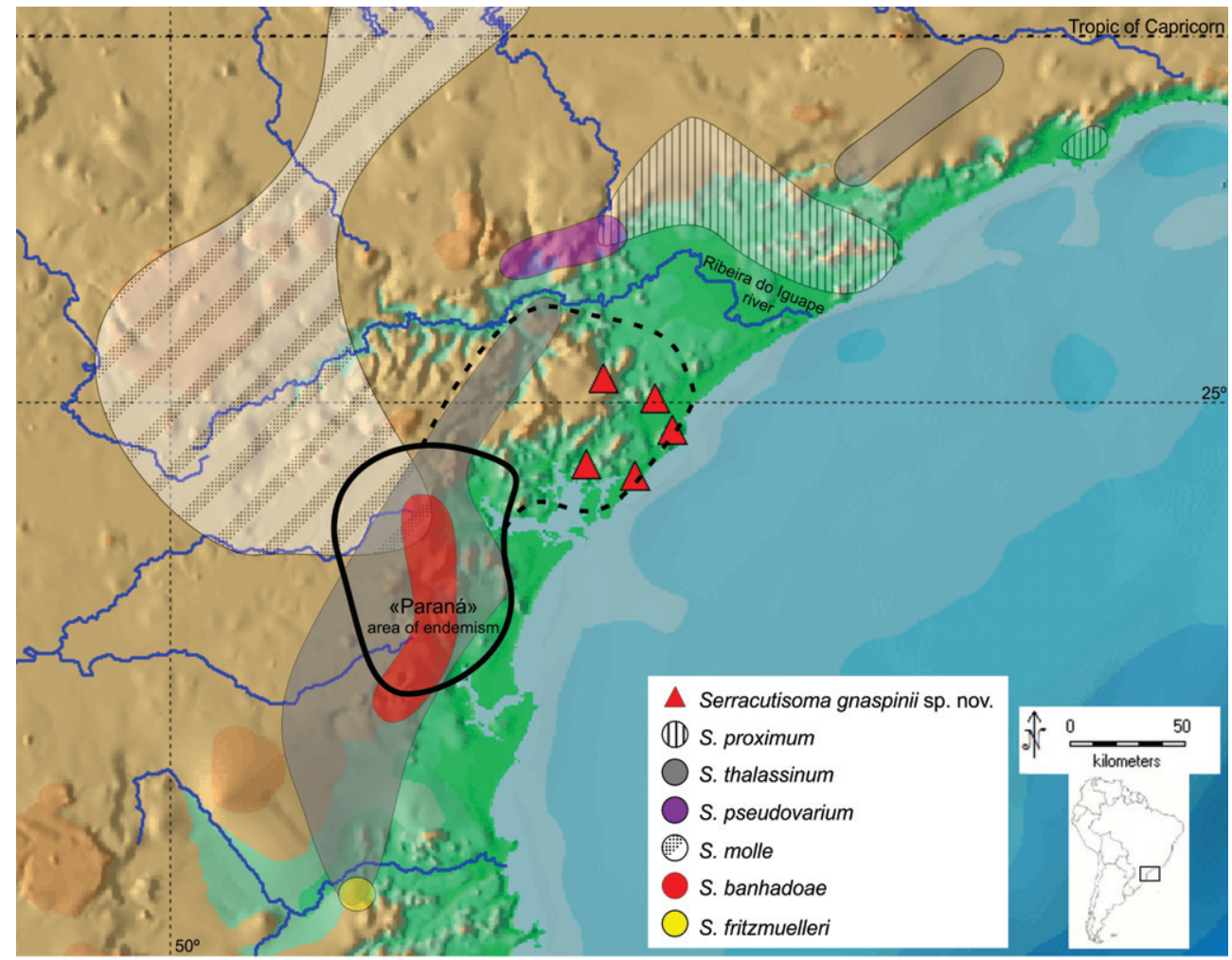

Figure 7. Records of the new species and the distributions of other species of S. proximum group in southern São Paulo, Paraná and north Santa Catarina states coasts. Ribeira do Iguape river flows between the sister-species S. proximum and S. gnaspinii sp. nov. Black solid line: limits of Congruence core of "Paraná" area of endemism; dashed line: limits of Maximum Region of Endemism of "Paraná" area of endemism (see DASILVA \& PINTO-DA-ROCHA 2011).

\section{LITERATURE CITED}

Ázara, L.N.; M.B. DaSilva \& R.L. FerReira. 2013. Description of Mitogoniella mucuri sp. nov. (Opiliones: Gonyleptidae) and considerations on polymorphic traits in the genus and Gonyleptidae. Zootaxa 3736: 69-81. doi:10.11646/ zootaxa.3736.1.3

Buzatto, B.A.; G.S. Requena; R.S. Lourenço; R. Munguía-Steyer \& G. Machado. 2011. Conditional male dimorphism and alternative reproductive tactics in a Neotropical arachnid (Opiliones). Evolutionary Ecology 25: 331-349. doi: 10.1007/s10682-010-9431-0

Caetano, D.S. \& G. Machado. 2013. The ecological tale of Gonyleptidae (Arachnida, Opiliones) evolution: phylogeny of a Neotropical lineage of armoured harvestmen using ecological, behavioural and chemical characters. Cladistics 29: 589-609. doi: 10.1111/cla.12009

Chelini, M.C.; R.H. Willemart \& P. Gnaspini. 2011. Caves as a Winter Refuge by a Neotropical Harvestman (Arachnida, Opiliones). Journal of Insect Behavior 24: 393-398. doi: 10.1007/s10905-011-9264-X
DaSilva, M.B. \& A.B. Kury. 2007. On the loss of sexual dimorphism in the Hernandariinae now including Multumbo Roewer and Piassagera Roewer (Opiliones, Gonyleptidae). Zootaxa 1558: 29-37.

DaSilva, M.B. \& P. Gnaspini. 2010. A systematic revision of Goniosomatinae (Arachnida: Opiliones: Gonyleptidae), with a cladistic analysis and biogeographical notes. Invertebrate Systematics 23: 530-624. doi: 10.1071/IS09022

DaSiLVA, M.B. \& R. PINTO-DA-Rocha. 2011. A história biogeográfica da Mata Atlântica: opiliões (Arachnida) como modelo para sua inferência, p. 221-238. In: C.J.B CaRvalHo \& E.A.B. AlmeIDA (Eds). Biogeografia da América do Sul, Padrões \& Processos. São Paulo, Editora Roca.

Machado, G. 2002. Maternal care, defensive behavior, and sociality in neotropical Goniosoma harvestmen (Arachnida, Opiliones). Insectes Sociaux 49: 388-393. doi:10.1007/ PL00012663

Machado, G.; R.L.G. Raimundo \& P.S. Oliveira. 2000. Daily activity schedule, gregariousness, and defensive behaviour in the Neotropical harvestman Goniosoma longipes (Opiliones: Gonyleptidae). Journal of Natural History 34: 587-596. 
Machado, G.; R. Pinto-da-Rocha \& A.A. Giaretta. 2002. Notes on taxonomy and biology of Goniosoma catarina sp. nov. (Opiliones: Gonyleptidae). Revista Ibérica de Aracnología 4: 17-22.

Nascimento, A.T.A.; L.A.J. Schmidlin; C.B. Valladares-Padua; E.R. Matushima \& L.M. Verdade. 2011. A Comparison of the Home Range Sizes of Mainland and Island Populations of BlackFaced Lion Tamarins (Leontopithecus caissara) Using Different Spatial Analysis. American Journal of Primatology 73: 1114-1126. doi: 10.1002/ajp.20977

Oliveira, R.M.; A.A. Zacaro; P. Gnaspini \& D.M. Cella. 2006. Cytogenetics of three Brazilian Goniosoma species: a new record for diploid number in Laniatores (Opiliones, Gonyleptidae, Goniosomatinae). The Journal of Arachnology 34, 435-443. doi:10.1636/S04-30.1

Pinto-da-Rocha, R.; M.B. DaSilva \& C. Bragagnolo. 2005. Faunistic similarity and historical biogeography of the harvestmen of southern and southeastern Atlantic Rain Forest of Brazil. The Journal of Arachnology 33: 290-299.

Willemart, R.H. \& P.Gnaspini. 2004. Spatial distribution, mobility, gregariousness, and defensive behavior in the Brazilian cave harvestman Goniosoma albiscriptum (Arachnida, Opiliones, Laniatores). Animal Biology 54: 221-235.

Submitted: 29.XI.2013; Accepted: 17.V.2014.

Editorial responsibility: Antonio D. Brescovit

ZOOLOGIA 31 (4): 370-376, August, 2014 